\title{
Drassodes lacertosus (O. Pickard- Cambridge, 1872) Türünün Sitogenetik Özelliklerinin Araştırılması
}

\author{
Hatice POYRAZ $^{1 *}$, Zübeyde KUMBIÇAK ${ }^{2}$ \\ ${ }^{1}$ Nevşehir Hacı Bektaş Veli Üniversitesi, Biyoloji Bölümü, Nevşehir \\ ${ }^{2}$ Nevşehir Hacı Bektaş Veli Üniversitesi, Moleküler Biyoloji ve Genetik Bölümü, Nevşehir \\ (ORCID: 0000-0001-7453-3342) (ORCID: 0000-0001-5949-1092)
}

\begin{abstract}
$\ddot{\mathbf{O z}}$
$\mathrm{Bu}$ çalışmada, farklı lokaliteler dikkate alınarak Nevşehir ilinden toplanan Gnaphosidae familyasına ait Drassodes lacertosus türünün karyolojik özellikleri ilk kez araştırılmıştır. Kromozom preparatlarının elde edilmesinde, Pekâr ve Krâl (2001) yöntemine göre klâsik giemsa boyama protokolü uygulanmıştır. Türün diploid kromozom sayısı $2 \mathrm{n}=22{ }^{\widehat{O}}$ ve eşey kromozom sistemi $\mathrm{X}_{1} \mathrm{X}_{2} 0$ 'dır. Otozomların ve eşey kromozomların morfolojisi telosentrik tipte bulunmuştur. Otozomal kromozomların relatif uzunlukları \% 9,46- \% 6,90 arasında kademeli olarak bir azalış gösterirken; eşey kromozomlarının relatif uzunlukları $X_{1}=\% \quad 10,76$ ve $X_{2}=\% \quad 6,67$ olarak tespit edilmiştir. Karyotipte $\mathrm{X}_{1}$ 'in en büyük kromozom olduğu, $\mathrm{X}_{2}$ 'nin ise en küçük kromozom olduğu belirlenmiştir. Mayoz bölünmenin profaz 1 ve metafaz 1 evresinde eşey kromozomları pozitif heteropiknotik özellik gösterirken; mayoz bölünmeye ait diğer evrelerde ise izopiknotik özellik göstermektedir. Mayoz bölünmeye ait evrelerin değerlendirilmesiyle birlikte $D$. lacertosus türünün kiyazmatik mayoz özelliği taşıdığı saptanmıştır. Sonuç olarak günümüze kadar elde edilen sitogenetik çalışmalarla birlikte; bu çalışmada, Drassodes lacertosus'a ait elde edilen ilk karyolojik bulgular, Drassodes cinsi için yeni veriler sunmakta ve Gnaphosidae familyasına ait türlerin sitogenetiğine katkılar sağlamaktadır.
\end{abstract}

Anahtar kelimeler: Gnaphosidae, kromozom, mayoz.

\section{Investigation of Cytogenetic Properties of Drassodes lacertosus (O. Pickard- Cambridge, 1872)}

\begin{abstract}
In this study, karyological characteristics of Drassodes lacertosus belong to Gnaphosidae family collected from Nevsehir province take into account different localites were investigated for the first time. In order to obtain chromosome preparations, classical giemsa staining protocol was applied accourding to the method of Pekâr and Krâl (2001). The diploid chromosome number of the species is $2 n=22 \hat{\jmath}$ and the sex chromosome system is $X_{1} X_{2} 0$. Morphology of autosomes and sex chromosomes was found to be of telocentric type. While the relative length of autosomal chromosomes gradually decreased between $\% 9,46$ and \% 6,90; the relative lengths of sex chromosomes were determined as $\mathrm{X}_{1}=\% \quad 10,76$ and $\mathrm{X}_{2}=\% \quad 6,67$. It was determined in the karyotype that $\mathrm{X}_{1}$ is the largest chromosome and $\mathrm{X}_{2}$ is the smallest chromosome. In the prophase 1 and metaphase 1 stage of the meiotic division, the sex chromosomes show positive heteropicnotic features; in other phases meiosis, it shows isopicnotic properties. With the evaluation of the phases of meiosis division, D. lacertosus species has been determined a chiasmatic meiosis. As a result, with the cytogenetic studies obtained to date; in this study, these first karyological finding of Drassodes lacertosus will provide new data about the Drassodes genus and contribute to the cytogenetics of the species belonging to the Gnaphosidae family.
\end{abstract}

Keywords: Gnaphosidae, chromosome, meiosis.

"Sorumlu yazar: hp.poyraz@gmail.com

Geliş Tarihi: 08.11.2019, Kabul Tarihi: 08.04.2020 


\section{Giriş}

Dünya'da bilinen hayvan türlerinin çoğunluğunu örümceklerin de dâhil olduğu Arthropoda (Eklembacaklılar) şubesi oluşturmaktadır. Örümcekler dünya üzerinde 120 familyada, 4163 cinste, toplamda ise 48410 türle temsil edilmektedir [1].

Hayvanlar âlemi arasında en çeşitli ve en bol karasal predatör olan örümcekler [2]; zehir üretebilen, avlarını yakalayabilmek için tuzaklar kurabilen, kamuflaj ustası olan Araneae takımına ait canlılardır. Örümcekler; Mesothelae, Mygalomorf ve Araneomorf olmak üzere üç temel monofiletik kökene ayrılmaktadır [3]. Tür sayısının fazla olması nedeniyle karyolojik bilgilerin, haplojin ve entelejin olarak iki alt gruba ayrılan Araneomorf örümcekler üzerinde yoğunlaştığı bilinmektedir.

Örümceklerde eşey kromozom sistemini ve karyotipini belirlemeye yönelik ilk sitogenetik çalışmalar 1900'lü yıllarda başlamıştır [4]. Daha sonraki yapılan çalışmalarla birlikte, günümüze kadar taksonomisi bilinen 48394 tür örümcekten sadece 868'i sitogenetik açıdan incelenmiştir. Yeryüzünde doğal bir yayılış alanına sahip olan ve sistematik açıdan 158 cins ve 2525 türle temsil edilen gnafozidlerin; sitogenetik olarak sadece 22 cins içerisinde 54 türü çalışılmıştır. Yapılan çalışmalarda Berinda (Roewer, 1928); Berlandina (Dalmas, 1922); Callilepis (Westring, 1874); Cesonia (Simon, 1893); Civizelotes (Senglet, 2012); Drassodes (Westring, 1851); Drassyllus (Chamberlin, 1922); Gnaphosa (Latreille, 1804); Haplodrassus (Chamberlin, 1922); Nomisia (Dalmas, 1921); Poecilochroa (Westring, 1874); Pterotricha (Kulczynski, 1903); Scotopheus (Simon, 1893); Trachyzelotes (Lohmander, 1944); Urozelotes (Mello- Leitao, 1938); Zelotes (Gistel, 1848) cinslerinin bazı türlerinde diploid sayı ve eşey kromozom sistemi ortaya konulmuştur. Nomisia, Haplodrassus ve Zelotes cinsleri ise en çok çalışılan gruplardır [5].

Örümceklerde diploid kromozom sayısı (Orsolobidae familyasında) $2 \mathrm{n}=5 \hat{\jmath}$ ve (Caponiidae familyasında) $2 n=136 \AA$ [6] arasında değişiklik göstermektedir. Örümcek karyotiplerinin karakteristik özelliklerinden birisi de çoklu eşey sisteminin baskınlığını belirtmesidir. Örümcekler üzerinde yapılan karyolojik çalışmaların birçoğunda $\mathrm{X}_{1} \mathrm{X}_{2} \mathrm{O}^{\Uparrow}$ ve $\mathrm{X}_{1} \mathrm{X}_{1} \mathrm{X}_{2} \mathrm{X}_{2} 0$ ㅇ şeklinde eşey kromozomları mevcut olmasına rağmen $\mathrm{X}_{1} \mathrm{X}_{2} \mathrm{X}_{3} 0, \mathrm{XY}, \mathrm{X} 0, \mathrm{X}_{1} \mathrm{X}_{2} \mathrm{Y}, \mathrm{X}_{1} \mathrm{X}_{2} \mathrm{X}_{3} \ldots \mathrm{X}_{13} 0$ çeşitlilikte de eşey kromozomları görülebilmektedir [5].

Yapılan çalışmalarda gnafozid örümceklerde diploid sayının 2n=21-30 $\overbrace{}^{\Uparrow}$ arasında olduğu tespit

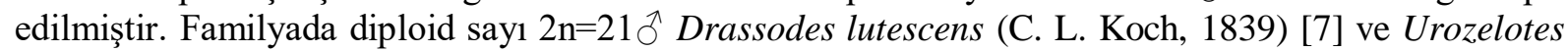
rusticus (L. Koch, 1872) [8]'da kaydedilirken; 2n=24 ${ }^{\Uparrow}$ Scotophaeus blackwalli (Thorell, 1871) [9]'de ve $2 \mathrm{n}=30$ ô ise Scotophaeus domesticus (Tikader, 1962) [8]'da bulunmuştur.

Bu çalışmada ülkemizde doğal yayılış alanına sahip Gnaphosidae familyasına ait Drassodes lacertosus (O. Pickard- Cambridge, 1872) türünün sitogenetik özelliklerinin (diploid kromozom sayısı, eşey kromozom sistemi, kromozomların mayoz bölünme sırasındaki davranışları ve kromozom morfolojisi) araştırılması amaçlanmıştır.

\section{Materyal ve Metot}

\subsection{Materyallerin toplanması}

Çalışmada kullanılan Drassodes lacertosus (O. Pickard- Cambridge, 1872) türüne ait örnekler, Nevşehir ilinden Mart-Mayıs (2014) ayları arasında yapılan arazi çalışmaları sonucunda, farklı lokalite ve habitatlar dikkate alınarak taş altlarından elle ya da aspiratör kullanılarak canlı olarak toplanmıştır (Tablo 1).

Taksonomik çalışmalarda morfolojik karakterler kadar karyolojik karakterler de son derece önemlidir. Çünkü yükseklik, bitki örtüsü, toprak yapısındaki farklılıklar ve iklim gibi ekolojik faktörler; morfolojik düzeyde de farklılıklara sebep olabilmektedir. Ancak bu değişikliklerden genetik yapı çok daha az etkilendiğinden karyolojik karakterler, taksonların sistematik kategorilerinin belirlenmesinde önemli veriler sunmaktadır [10-11]. 
Tablo 1. Çalışmada kullanılan örneklerin toplandığı lokalitelerin koordinatları

\begin{tabular}{|c|c|c|}
\hline Tür & Örnek Sayısı & Koordinat Bilgileri \\
\hline \multirow{3}{*}{$\begin{array}{l}\text { Drassodes lacertosus } \\
\text { (O. Pickard- Cambridge, } 1872\end{array}$} & $10^{\lambda}$ & $\begin{array}{l}\text { Göre, Nevşehir; } \\
38^{\circ} 35^{5} 48.84^{\prime \prime} \mathrm{K} \text { ve } \\
34^{\circ} 43^{\prime} 40.60^{\prime \prime} \mathrm{D}\end{array}$ \\
\hline & $10^{\pi}$ & $\begin{array}{c}\text { Acıgöl, Nevşehir; } \\
38^{\circ} 3222.60^{\prime \prime} \mathrm{K} \text { ve } \\
34^{\circ} 3255.93^{\prime \prime} \mathrm{D}\end{array}$ \\
\hline & $2 \hat{0} 0^{\pi}$ & $\begin{array}{c}\text { Mazı, Nevşehir; } \\
38^{\circ} 27^{7} 56.04^{\prime \prime} \mathrm{K} \text { ve } \\
34^{\circ} 5020.39^{\prime} \mathrm{D}\end{array}$ \\
\hline
\end{tabular}

\subsection{Deneysel çalıșmalar ve örümceklerde kromozom inceleme}

Arazi çalışmaları sırasında örümceklere hiçbir işlem yapılmamış ve örümcekler 5-10 cm ebatlarındaki tüplere alınarak canlı bir şekilde laboratuvara getirilmiştir. Tüpler içerisine nemli pamuk konulmuştur. Örümcekler diseksiyon yapılıncaya kadar canlı olarak bekletilmiş ve sirke sinekleri ile haftada iki kez beslenmiştir.

Günümüze kadar yapılan mevcut çalışmalarda örümcekler için metafaz kromozomların incelenmesi amacıyla uygun doku olarak gonadlar kullanılmaktadır. Çünkü gonadlar bölünmekte olan çok sayıda hücre içermektedir [12].

Kromozom preparatlarının yapılması Pekâr ve Krâl (2001) yöntemine göre gerçekleştirilmiştir [13]. Laboratuvara getirilen canlı hâldeki ergin erkek örümcekler seçilerek, pens yardımıyla prosoma bölgesinden sıkılarak öldürülmüştür. Örümceklerin gonadları stereomikroskop altında fizyolojik tuz çözeltisi içerisinde diseksiyon yapılarak çıkarılmıştır. Gonadlar saf su içerisinde $20 \mathrm{dk}$. bekletilerek hücrelerin şişmesi sağlanmıştır (Hipotonik uygulama). Daha sonra dokular, 3:1 oranında hazırlanmış etanol/asetik asit çözeltisi içerisinde $10 \mathrm{dk}$. ve $20 \mathrm{dk}$. olmak üzere iki kez fikse edilmiştir.

$\%$ 96'llk etanolde $60 \mathrm{dk}$. bekletilerek temizlenen lamların üzerine birkaç damla \% 60'llk asetik asit damlatılarak hazırlanan karışım bir iğne yardımıyla 1 sıtıcı tabla $\left(42^{\circ} \mathrm{C}\right)$ üzerinde yayılarak gonadların eritilmesi sağlanmıştır. Hazırlanan preparatlar, ardından fosfat tampon içeren $(\mathrm{ph}=6,8)$ Giemsa boyasıyla $50 \mathrm{dk}$. boyanmıştır.

Preparatlardaki kromozomların mitotik ve mayotik evreleri 1şık mikroskobundaki 10X büyütmede tespit edilmiş ve kromozomların ayrıntılı olarak incelenmesi 100X büyütmede gerçekleştirilmiştir. Kromozom fotoğrafları CellSens programı (BX53 Olympus 1şık mikroskobu 100X büyütmede) ile çekilmiş ve relatif uzunlukları ise mikrometrik $(\mu \mathrm{m})$ olarak CellSens programı ile ölçülerek her bir kromozom çiftinin \% değeri hesaplanmıştır. Karyotip fotoğrafı ise Adobe Photoshop CS3 programı kullanılarak hazırlanmıştır.

\section{Bulgular ve Tartışma}

Bu çalışmada Drassodes lacertosus türünün erkek bireylerde diploid kromozom sayısı ve eşey kromozom sistemi tespit edilmiştir. Karyotip hazırlanırken otozomlar relatif uzunluklarına göre büyükten küçüğe doğru sıralanmış ve eşey kromozomları ise bu sıralamanın en sonunda yer almıştır. Türe ait diploid kromozom sayıs $2 \mathrm{n}=22 \hat{\gamma}$, eşey kromozom sistemi $\mathrm{X}_{1} \mathrm{X}_{2} 0$, kromozom morfolojisi ise telosentrik tipte ve karyogramı ise şekil 1'de gösterilmiştir.

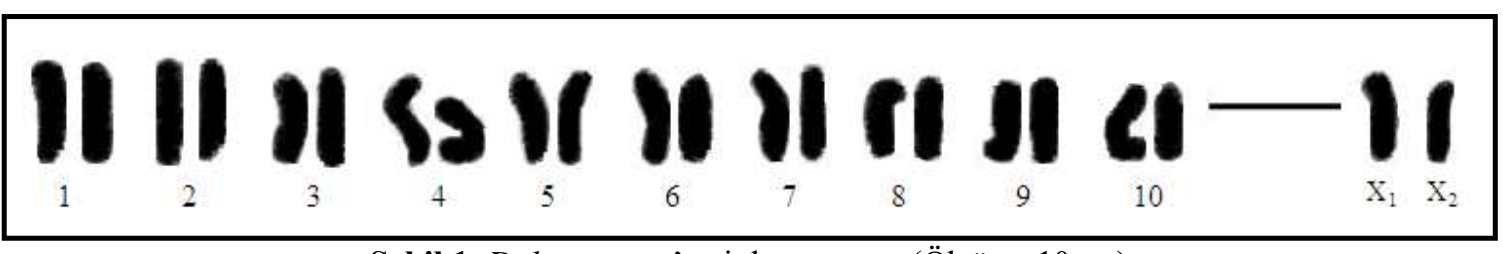

Şekil 1. D. lacertosus'a ait karyogram (Ölçüm=10 $\mu \mathrm{m})$ 
Otozomal çiftlerin toplam relatif uzunlukları kademeli bir azalış göstererek \% 9,49- \% 6,90 arasında değişiklik göstermektedir. Karyotipte en büyük kromozom olan $\mathrm{X}_{1}$ ' in relatif uzunluğu \% 10,76 ve en küçük kromozom olan $\mathrm{X}_{2}$ 'nin relatif uzunluğu ise \% 6,67 olarak bulunmuştur (Tablo 2).

Mayoz bölünmeye ait profaz evresinde (zigoten ve pakiten safhasında) eşey kromozomları otozomlardan daha fazla kısalıp kalınlaştığı için daha koyu boyanmasıyla birlikte pozitif heteropiknotik özellik sergilemektedir (Şekil 2-a ve Şekil 2-b).

Mayotik diploten evresinde ise 10 otozomal bivalent (bivalentler bir ya da iki kiyazmaya sahiptir)- $X_{1}, X_{2}$ olmak üzere iki adet univalent mevcuttur. Ayrıca diploten evresinde ring (halka) bivalentler de görülebilmektedir (Şekil 2-c). Türün diploid sayısının belirlenmesi ve karyotip hazırlanması amaciyla 10 spermatogonial metafaz evresi incelenmiştir. Metafaz evresinde kromozomlar tam olarak sayılabilmekte ve türe ait diploid sayı ise $2 n=22{ }^{\lambda}\left(20+X_{1} X_{2}\right)$ şeklindedir (Şekil 2-d).

Tablo 2. Çalışılan türün kromozomal kol uzunlukları, relatif uzunlukları ve kromozom morfolojisi

\begin{tabular}{cccc}
\hline Kromozom çifti & $\begin{array}{c}\text { Toplam uzunluk } \\
\text { (Uzun kol+ kisa kol) }\end{array}$ & Relatif uzunluk (\%) & Kromozom morfolojisi \\
\hline 1 & 5,25 & 9,46 & Telosentrik \\
2 & 5,06 & 9,12 & Telosentrik \\
3 & 4,80 & 8,65 & Telosentrik \\
4 & 4,71 & 8,49 & Telosentrik \\
5 & 4,67 & 8,41 & Telosentrik \\
6 & 4,59 & 8,27 & Telosentrik \\
7 & 4,36 & 7,86 & Telosentrik \\
8 & 4,30 & 7,75 & Telosentrik \\
9 & 4,25 & 7,66 & Telosentrik \\
10 & 3,83 & 6,90 & Telosentrik \\
$\mathrm{X}_{1}$ & 5,97 & 10,76 & Telosentrik \\
$\mathrm{X}_{2}$ & 3,68 & 6,67 & Telosentrik \\
\hline
\end{tabular}
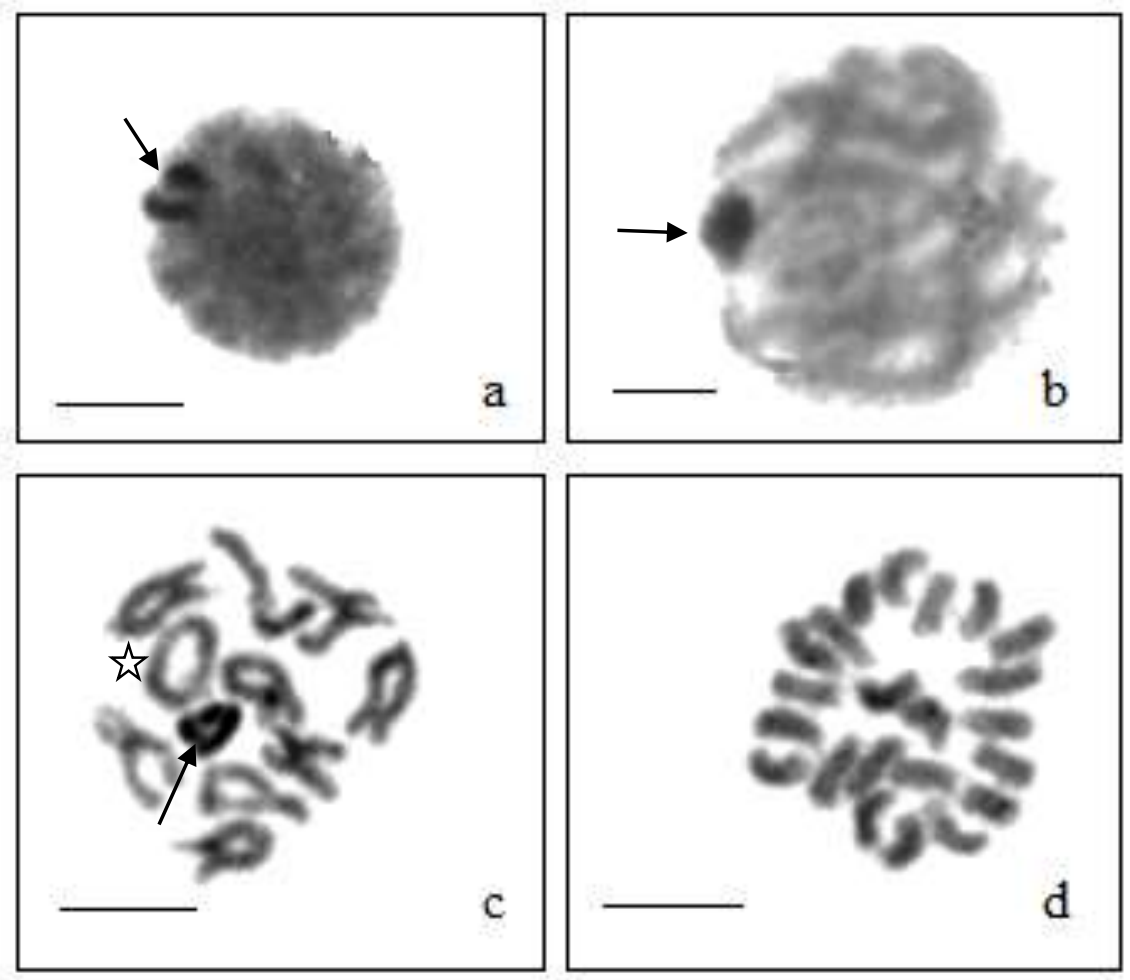

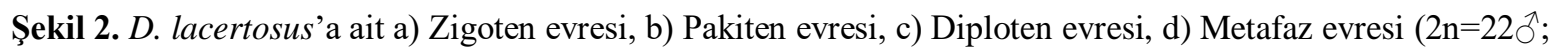
ok işareti ile gösterilenler eşey kromozomları, yıldız işareti ile gösterilen ise halka bivalenttir) 
Bu çalışmada, D. lacertosus türünün mayoz bölünme özellikleri ve karyotip verileri ilk kez çalışılmıştır. Elde edilen sonuçlarla birlikte Gnaphosidae familyasına ait diğer türlerin çoğunluğunun diploid kromozom sayısının $2 \mathrm{n}=22$ olarak bulunması, familya içerisinde bu sayının korunduğunu düşündürmektedir. $\mathrm{Bu}$ nedenle bu familyaya ait türlerde taksonomik sorunlarla karşılaşıldığında, sitogenetik karakterler önemli yer tutacaktır.

\section{Sonuç ve Öneriler}

Yer örümcekleri olarak da bilinen gnafozid örümcekler, ülkemizde 32 cins ve 147 türle temsil edilmektedir. Bunlardan 10 tanesi ise Drassodes cinsine ait taksonlardır (Drassodes bifidus Kovblyuk \& Seyyar, 2009; Drassodes cupreus (Blackwall, 1834); Drassodes difficilis (Simon, 1878); Drassodes lacertosus (O. Pickard-Cambridge, 1872); Drassodes lapidosus (Walckenaer, 1802); Drassodes lutescens (C. L. Koch, 1839); Drassodes pubescens (Thorell, 1856); Drassodes serratichelis (Roewer, 1928); Drassodes similis Nosek, 1905; Drassodes villosus Thorell, 1856) [14].

Gnafozid örümcekler mayoz bölünme davranışları açısından değerlendirildiğinde; telosentrik ya da akrosentrik tipte kromozom morfolojisine sahip olmas1 ve $\mathrm{X}_{1} \mathrm{X}_{2}{ }^{\top} / \mathrm{X}_{1} \mathrm{X}_{1} \mathrm{X}_{2} \mathrm{X}_{2} \odot$ şeklinde eşey sisteminin görülmesi dikkat çekmektedir. Bunun yanında $\mathrm{X} 0{ }^{\wedge} / \mathrm{XX}$ + eşey sistemine de rastlanılmıştır. $\mathrm{X} 0$ eşey sisteminde, $\mathrm{X}$ kromozomunun $\mathrm{X}_{1}$ ve $\mathrm{X}_{2}$ 'nin sentrik füzyon sonucu oluştuğu önerilmektedir [4]. Ayrıca mayoz bölünmenin profaz 1 evresinde (leptotenden diyakineze kadar) eşey kromozomları otozomlardan ayırt edilerek pozitif heteropiknotik özellik göstermesi, anafaz 1, profaz 2 ve metafaz 2 evrelerinde eşey kromozomlarının izopiknotik özellikte olması familya için genel karakteristik özellikleri yansıtmaktadır. Bununla birlikte araneomorf örümceklerde kiyazmatik mayoz özelliğinin sıklıkla görüldüğü ve diploten, diyakinez ve metafaz 1 evresinde bivalentlerin genelde tek kiyazmaya sahip oldukları tespit edilmiştir [15].

Yapılan literatür taramalarında ise $D$. lacertosus türüne ait karyolojik verilere rastlanılmamıştır. Drassodes cinsine ait karyotipi yapılan türler tablo 3 'te gösterilmiştir. Bu çalışmamızda D. lacertosus'a ait diploid sayının 2n=22 olmas1, mayoz bölünmenin profaz 1 evresinde (Zigoten, pakiten ve diploten evresinde) eşey kromozomların otozomlardan ayırt edilmesi (pozitif heteropiknotik özellik göstermesi), diploten evresinde 10 otozomal bivalent ve iki univalent eşey kromozomlarının görülmesi ve kiyazmatik mayoz özelliğini yansıtması familya içerisindeki uyumu göstermektedir.

Tablo 3. Drassodes cinsine ait karyotipi yapılan türler

\begin{tabular}{|c|c|c|c|}
\hline Tür adı & Diploid sayı & Eşey kromozom sistemi & Referans \\
\hline $\begin{array}{c}\text { Drassodes lapidosus } \\
\text { (Walckenaer, 1802) }\end{array}$ & $2 n=22 \sigma^{\lambda}$ & $\mathrm{X}_{1} \mathrm{X}_{2} \mathrm{O}$ & $\begin{array}{l}\text { Hackman, } 1948 \text { [16]; } \\
\text { Azgın, } 2015 \text { [17] }\end{array}$ \\
\hline $\begin{array}{l}\text { Drassodes pubescens } \\
\quad \text { (Thorell, 1856) }\end{array}$ & $2 n=22{ }^{\lambda}$ & $\mathrm{X}_{1} \mathrm{X}_{2} \mathrm{O}$ & $\begin{array}{c}\text { Kumbiçak et al., } 2009 \\
{[18]}\end{array}$ \\
\hline $\begin{array}{l}\text { Drassodes lutescens } \\
\text { (C. L. Koch, 1839) }\end{array}$ & $2 n=210^{\lambda}$ & $\mathrm{X} 0$ & $\begin{array}{c}\text { Kumbiçak et al., } 2014 \\
\text { [7] }\end{array}$ \\
\hline Drassodes sp. & $2 n=22{ }^{\lambda}$ & $\mathrm{X}_{1} \mathrm{X}_{2} \mathrm{O}$ & Suzuki, 1864 [19] \\
\hline Drassodes sp. & $2 \mathrm{n}=21 \mathrm{O}^{-1}$ & X0 & $\begin{array}{c}\text { Srivastava\& Shukla, } \\
1986[8]\end{array}$ \\
\hline $\begin{array}{l}\text { Drassodes serratichelis } \\
\quad \text { (Roewer, 1928) }\end{array}$ & $2 n=22 \overbrace{}^{\lambda}$ & $\mathrm{X}_{1} \mathrm{X}_{2} \mathrm{O}$ & $\begin{array}{c}\text { Kumbiçak ve Poyraz, } \\
2020[20]\end{array}$ \\
\hline $\begin{array}{l}\text { Drassodes bifidus } \\
\text { (Kovblyuk ve Seyyar, } \\
\text { 2009) }\end{array}$ & $2 n=22{ }^{-1}$ & $\mathrm{X}_{1} \mathrm{X}_{2} \mathrm{O}$ & $\begin{array}{c}\text { Kumbiçak ve Poyraz, } \\
2020[20]\end{array}$ \\
\hline
\end{tabular}

Sonuç olarak; D. lacertosus türünün diploid sayısı, eşey kromozom sistemi, kromozom morfolojisi ve mayotik bölünme sırasındaki davranışları sitogenetik açıdan ilk kez araştırılmıştır. Tür sayısının fazla olmasına rağmen sadece $\% 1,8^{\prime}$ lik kısmının sitogenetik olarak incelenmesi, bu alandaki çalışmalarının henüz istenilen düzeye ulaşmadığını göstermektedir. Böylece elde edilen bu verilerle birlikte, Araneomorf örümceklerle ilgili karyolojik çalışmaların arttırılması gerektiği düşünülmektedir. 


\section{Teşekkür}

Arazi çalışmaları ve laboratuvar çalışmaları sırasında yardımlarını esirgemeyen Sayın Dr. Öğr. Üyesi Ümit KUMBIÇAK'a ve doktora öğrencisi Şeyma CIVAN'a teşekkür ederim.

\section{Yazarların Katkısı}

Yazarlar arazi çalışmalarında, deneysel çalışmalarda ve makale yazımında eşit katkı sağlamıştır. Ayrıca makalenin gerekli düzenlemelerin yapılmasında Doç. Dr. Zübeyde KUMBIÇAK yüksek katkı sağlamıştır.

\section{Çıkar Çatışması Beyanı}

Yazarlar arasında herhangi bir çıkar çatışması bulunmamaktadır.

\section{Araştırma ve Yayın Etiği Beyanı}

Yapılan çalışmada araştırma ve yayın etiğine uyulmuştur. $\mathrm{Bu}$ araştırma etik kurul izni gerektirmemektedir.

\section{Kaynaklar}

[1] Platnick N.I. 2020. World Spider Catalog, Versiyon 21.0. Natural History Museum Bern., doi: 10.24436/2, online at http://wsc.nmbe.ch (Erişim tarihi: 08.04.2020).

[2] Coddington J.A., Levi H.W. 1991. Systematics and Evolution of Spiders (Araneae). Annu. Rev. Ecol. Syst., 22 (1): 565-592.

[3] Bayram A., Allahverdi H. 1999. Tarımsal Ekosistemlerde Örümceklerin Habitat Tercihleri Üzerine. Cent. Ent. Stud. Misc., 58: 1-7.

[4] Araujo D., Schneider M.C., Paula-Neto E.P., Cella M.D. 2012. Sex Chromosomes and Meiosis in Spiders, A Review. In A. Swan (ed.), Meiosis-Moleculer Mechanisms and Cytogenetic Diversity, In Tech, Rijeka, Croatica, pp. 87-109, doi:10.5772/31612.

[5] Araujo D., Schneider M.C., Paula-Neto E., Cella D.M. 2020. The Spider Cytogenetic Database, online at www.arthropodacytogenetics.bio.br/spiderdatabase (Erişim tarihi: 08.04.2020).

[6] Krâl J., Forman M., Korinkova T., Reyes Lerma A.C., Haddad C.R., Musilova J., Rezac M., Avila Herrera I.M., Thakur S., Dippenaar Schoeman A.S., Marec F., Horova L., Bures P. 2019. Insights into the Karyotype and Genome Evolution of Haplogyne Spiders Indicate a Polyploid Origin of Lineage with Holokinetic Chromosomes. Scientific Reports, 9 (1): 3001.

[7] Kumbıçak Z., Ergene S., Kumbıçak Ü., Ekiz E. 2014. A Chromosomal Analysis of Five Spider Species (Araneae: Gnaphosidae, Miturgidae and Philodromidae) from Turkey. Caryologia, 67 (2): 155-159.

[8] Srivastava M., Shukla S. 1986. Chromosome Number and Sex- Determining Mechanism in FortySeven Species of Indian Spiders. Chromosome Information Service, 41: 23-26.

[9] Mittal O.P. 1967. Karyological Studies on the Indian Spiders VII. Mitosis and Meiosis in Two Species Belonging to the Family Gnaphosidae. Genetica, 38 (4): 516-520.

[10] Aydın Ö.S., Dirmenci T. 2004. Endemik Nepeta nuda l. subsp. lydiae ph davis Alt Türünün Morfoloji ve Karyolojisinin İncelenmesi. Balıkesir Üniversitesi Fen Bilimleri Enstitüsü Dergisi, 6 (1): 26-32.

[11] Poyraz H. 2017. Gnaphosidae Familyasına Ait Bazı Örümcek Türleri Üzerinde Sitogenetik Araştırmalar. Yüksek Lisans Tezi, Nevşehir Hacı Bektaş Veli Üniversitesi, Fen Bilimleri Enstitüsü, Nevşehir.

[12] Kumbıçak Z. 2010. Kumbıçak Z. 2010. Türkiye'de Bazı Örümceklerde Karyotip ve Eşey Kromozomlarının Belirlenmesi Üzerine Araştırmalar. Doktora Tezi, Gaziantep Üniversitesi, Fen Bilimleri Enstitüsü, Gaziantep.

[13] Pekâr S., Krâl J. 2001. A Comparative Study of the Biology and Karyotypes of Two Central European Zodariid Spiders (Araneae, Zodariidae). Journal of Arachnology, 29 (3): 345-353. 
[14] Bayram A., Kunt K.B., Danışman T. 2019. The Checklist of the Spiders of Turkey. Version 19.5, online at http://www.spidersofturkey.info (Erişim tarihi: 08.04.2020).

[15] Kumbıçak Z. 2019. First Cytogenetic Analysis of Eratigena agrestris (Araneae: Agelenidae) from Turkey. Journal of Insect Science, 19 (5): 1-4.

[16] Hackman W. 1948. Chromosomenstudien an Araneen Mit Besonderer Berücksichtigung Der Geschlechtschromosomen. Acta Zoologica Fennica, 54: 1-101.

[17] Azgın E. 2015. Bazı Yer Örümceklerinin (Arachnida: Araneae) Karyotip Analizlerinin Araştırılması. Yüksek Lisans Tezi, Niğde Üniversitesi, Fen Bilimleri Enstitüsü, Niğde.

[18] Kumbıçak Z., Ergene S., Saygıdeğer S. 2009. Chromosomal Data on Six Araneomorph Spiders Belonging to the Families Lycosidae and Gnaphosidae (Araneae: Araneomorphae). Zoology in the Middle East, 48 (1): 89-96.

[19] Suzuki S. 1954. Cytological Studies in Spiders III. Studies on the Chromosomes of Fifty-Seven Species of Spiders Belonging to Seventeen Families with General Considerations on Chromosomal Evolution. Journal of Science of the Hiroshima University, 15 (2): 23-136.

[20] Kumbiçak Z., Poyraz H. 2020. A Cytogenetical Study on Two Ground Spider Species (Gnaphosidae: Drassodes) from Nevşehir District. Pakistan J. Zool., 52 (2): 513-517. 